\title{
Undiagnosed HIV in women attending a sexual health clinic for non-barrier methods of contraception. Two case studies
}

\author{
Martin Jones, RGN, MSc, Clinical Nurse Specialist/Co-ordinator, Sexual Health, Eastbourne Sexual Health Clinic, Eastbourne, UK \\ Correspondence: Martin Jones, Sexual Health, Eastbourne Downs Primary Care Trust, Avenue House, The Avenue, \\ Eastbourne, East Sussex BN21 3XY, UK. Tel/Fax: +44 (0) 1323 444165. E-mail: martin.jones@eastbournedownspct.nhs.uk
}

(Accepted $14^{\text {th }}$ October 2002)

Journal of Family Planning and Reproductive Health Care 2003; 29(1): 31-32

\begin{abstract}
Approximately one-third of human immunodeficiency virus (HIV) cases in the UK remain undiagnosed. More than half of new diagnoses in the last 2 years have been acquired through heterosexual sexual intercourse. Two cases of women with identified risk factors for HIV infection, who presented for contraception and were later found to be HIVpositive, are described. It is suggested that providers of contraception are well placed to identify clients at high risk of HIV and to recommend HIV testing.
\end{abstract}

\section{Key message points}

- Approximately one-third of HIV infections in the UK remain undiagnosed.

- More than half the new diagnoses of HIV made in the last 2 years were acquired through heterosexual sexual intercourse.

- Two case reports demonstrate that clients with undiagnosed HIV infection attend clinics for non-barrier methods of contraception.

- Contraceptive services are well placed to identify clients at high risk for HIV infection, and to recommend HIV testing.

\section{Introduction}

As long ago as 1989, family planning was identified by the International Planned Parenthood Federation (IPPF) as having an important role to play in the control of human immunodeficiency virus (HIV). ${ }^{1}$ Currently in the UK approximately one-third of HIV infections remain undiagnosed, ${ }^{2}$ with more than half the newly diagnosed cases being acquired through heterosexual sexual intercourse. ${ }^{3}$ The National Strategy for Sexual Health and $H I V$ includes as an aim 'the reduction of the proportion of undiagnosed cases of HIV infection'. ${ }^{4}$ Late diagnosis of $\mathrm{HIV}$ is associated with greater morbidity and mortality, and denies opportunities for targeted safer sex discussion. The introduction of HIV testing as a routine part of antenatal care is helping to identify some of the undiagnosed cases, resulting in fewer cases of vertical transmission of HIV infection. 5

Family planning clinics (FPCs) and 'one-stop' sexual health clinics see clients requesting contraception and preconceptual advice, as do primary care services. The prevalence of HIV among FPC attenders may be low. ${ }^{6}$ However, contraceptive services are well placed to extend discussion about HIV testing to their clients, the majority of whom are in favour of this initiative. ${ }^{7}$ This is not necessarily easy in busy clinics when seeing clients whose primary reason for attendance is for contraception. The Eastbourne Sexual Health Clinic is a 'one-stop' sexual health clinic combining family planning and genitourinary medicine. ${ }^{8}$ The cases of two women who presented for non-barrier methods of contraception and were later diagnosed HIVpositive are presented below. Experience of managing these cases 'under one roof' has raised awareness of the need to offer HIV testing to clients at high risk of HIV infection who attend for contraception.

\section{Case reports}

Case 1

A woman from a sub-Saharan country presented for removal of a Norplant, which had been inserted 6 years previously. She reported that her husband had died and that she was not in a sexual relationship. An uneventful removal took place and cervical cytology was discussed.

Two weeks later, she was admitted to hospital with breathlessness and was diagnosed with miliary tuberculosis with involvement of lungs, pleura and cerebrospinal fluid. She was HIV-positive with a CD4 count of $6 / \mathrm{mm}^{3}(6 \%)$ and a viral load or 439662 copies/ml. Cervical cytology performed 1 month after discharge from hospital showed severe dyskaryosis which was treated in a colposcopy clinic.

She has made a good recovery and is, after 16 months on highly active antiretroviral therapy, asymptomatic with a CD4 count of $163 / \mathrm{mm}^{3}(19 \%)$ and an undetectable viral load. She continues to visit the sexual health clinic and is discussing the possibility of a new sexual relationship and safer sex.

Case 2

A woman from a sub-Saharan country presented for contraception as she was starting a new sexual relationship. She was given an injection of Depo Provera, which she continued to have regularly for the next year. She reported some postcoital bleeding in the first few weeks, which had settled by the time of her second injection. She was also treated for an episode of bacterial vaginosis during this time.

Eleven months after her first presentation to the clinic she was admitted to hospital with a tuberculous pleural effusion, which responded well to treatment. She subsequently tested positive for HIV with a CD4 count of $110 / \mathrm{mm}^{3}(18 \%)$ and a viral load of $248000 / \mathrm{ml}$. It is planned that she will start highly active antiretroviral therapy in the near future.

\section{Discussion}

Despite being seen in a 'one-stop' clinic with its advantages of offering a HIV testing service alongside family planning, both these women were diagnosed HIV-positive only after 
admission to hospital with tuberculosis. Both had identifiable risk factors for HIV, which were known at the time of their consultations for contraception. The clinic has revised its approach to HIV testing and now offers this service to all clients with an identified risk factor, regardless of the primary reason for attendance. One of the major risk factors in clients attending for contraception is unprotected sexual intercourse in a country with high HIV prevalence.

This approach seems feasible not only in one-stop sexual health clinics but also in dedicated FPCs, and in general practice where large numbers of clients requesting non-barrier methods of contraception are seen. Clients with a history of unprotected sexual intercourse from countries with high HIV prevalence should be identified, HIV testing discussed, with onward referral where necessary. Condoms should be provided.
Statements on funding and competing interests

Funding. None identified.

Competing interests. None identified.

References

1 Gordon G, Klouda T. Preventing a crisis: AIDS and family planning work. London: Macmillan, 1989.

2 Public Health Laboratory Service. AIDS/HIV Quarterly Surveillance Tables: cumulative UK data to end June 2002. www.phls.org.uk

3 Public Health Laboratory Service. 33500 people are living with HIV in the UK. Press release 2 July 2002. www.phls.org.uk

4 Department of Health. The national strategy for sexual health and HIV. London: Department of Health, 2001.

5 Fieldhouse R. HIV prevalence in UK: latest data 4 December 2001. www.aidsmap.com

6 Goldberg D, Carr S, Cameron S, et al. HIV infection among family planning clinic attenders in Glasgow: why prevalence has remained low in this general population group. Sex Transm Infect 1998; 74: 50-53.

7 Bergenstom A, Sherr L, Okolo S. HIV testing and prevention: family planning clinic attenders in London. Sex Transm Infect 1999: 75: 130.

8 Jones $\mathrm{M}$. Integrating family planning with genitourinary medicine: developing an holistic sexual health clinic in Eastbourne. Br J Fam Plann 2000: 26: 221-224.

\section{SHORT COMMUNICATIONS}

\section{Experience of reversal of sterilisation at Glasgow Royal Infirmary}

Sivaraman Prabha, MBBS, DFFP, Senior House Officer, Department of Obstetrics and Gynaecology, Glasgow Royal Infirmary, Glasgow, UK; C Burnett Lunan, MD, FRCOG, Consultant Gynaecologist and Obstetrician, Glasgow Royal Infirmary, Glasgow, UK; Robert Hill, BSc, Epidemiologist, Scottish Centre for Infection and Environmental Health, Glasgow, UK

Correspondence: Dr S Prabha, Department of Obstetrics and Gynaecology, Glasgow Royal Infirmary, 84 Castle Street, Glasgow G4 OSF, UK. E-mail: prabhas3@hotmail.com

(Accepted $1^{\text {st }}$ November 2002)

Journal of Family Planning and Reproductive Health Care 2002: 29(1): 32-33

\begin{abstract}
Objective. To review experience at the Glasgow Royal Infirmary with regard to women who underwent reversal of sterilisation, to obtain a profile of these women and to evaluate the procedure itself in terms of safety and restoration of fertility.
\end{abstract}

Design. A retrospective study based on case records from the Glasgow Royal Infirmary and from the Glasgow Royal Maternity Hospital, both of which share the same catchment area.

Participants. Eighty-five women underwent reversal of sterilisation between 1 January 1994 and 31 December 1998 at the Glasgow Royal Infirmary. Follow-up at the Glasgow Royal Maternity identified 43/85 women.

Methods. Patients were identified from relevant theatre log books and from records at the maternity hospital until December 2000 and their case notes reviewed.

Results. Having a new partner was responsible for $90 \%$ of requests. Median age at request for reversal was 34 years and most had been sterilised before the age of 30 years. There were few postoperative complications. Pregnancy occurred in at least $43 \%$ of women.

Conclusion. Reversal of sterilisation is a safe and effective method of restoring fertility. The actual incidence of pregnancy after reversal is likely to be higher than the $43.5 \%$ recorded due to difficulties in achieving $100 \%$ follow-up.

\section{Introduction}

Tubal occlusion remains the most cost-effective and convenient choice for many parous women seeking contraception, in spite of the increasing availability of reversible methods. Although the reversibility is not an idea that is encouraged at the time of sterilisation, up to $14 \%{ }^{1}$ of these women regret the decision and request reversal of the procedure.

This is a review of our experience at the Glasgow Royal Infirmary, Glasgow, UK with regard to reversal of sterilisation during a 5-year period from 1994 to 1998. During this period, an average of 280 sterilisations and 17 reversals per year had been carried out in this hospital. The objectives were to obtain a profile of women requesting reversal of sterilisation, and to evaluate the procedure itself in terms of safety and restoration of fertility, although the numbers were relatively small and the conclusions tentative in this regard.

\section{Methods}

A list of all patients who underwent reversal of sterilisation between 1994 and 1998 was obtained from theatre logbooks at the Glasgow Royal Infirmary. The case records of all these women were used to procure relevant data on the details of the request, work-up and procedure. A follow-up after reversal from the date of surgery until 2000 using case records from the Glasgow Royal Maternity Hospital, which 